bleeding points on the surface and also sticky pus-like material, especially in the furrows. In size the tumour is larger than a fist and there is on the under surface the mark indicating the division of what looks like a pedicle.

Microscopically one can recognise areas of degeneration in the midst of fairly well preserved tissue which gets scantier towards the central portion of the growth, as judged from sections taken from this part. The undegenerated portions consist of cells poor in protoplasm and with deeply staining nuclei which are oval or rounded. Mitotic figures of various kinds have been observed. The cellular masses are traversed by blood sinuses and profuse haemorrhages are present. The degenerated portions show " ghosts" of cells with nuclei either entirely unstained or slightly so, being in places piknotic. Islets of fairly well preserved cells are discernible here and there in these areas, arranged around lumina that do not contain any blood. One fails to find regular " rosettes." There are here and there cells with large elongated ovoid faintly-staining nuclei with fibrils and here and there endothelial cells are present. In the neighbourhood of ulcerated areas polynuclear leucocytes are found penetrating the substance of the growth.

Diagnosis.-Neuro-epithelioma of the retina.

The only peculiarity in the case in point was the unusual size of the tumour and the short period during which it attained such a huge size. Similar cases are reported in "Surgical Pathology," by McFarland, and in Banerjee's " Text Book of Pathology."

I am indebted to Dr. Noronha, Pathologist, B. J. Medical School, for having kindly lent me two micro-photographs of sections of the tumour.

\title{
ANNOTATION
}

\section{The other half of the Story}

It was at one time the habit of a certain section of the legal community to concoct an apparently impossible story and demand some rational explanation of the sequence of events. The best known one, reputed to be true, concerns a girl and her mother who visited Paris at the time of the great exhibition. They had come from abroad and took rooms at an hotel where they had dinner together. Their rooms were next door to each other, and they retired to bed at about 10 o'clock in the evening. When the daughter awoke next morning she tried to go to her mother's room 
to have early tea with her, but found the communicating door locked. She rang for the chambermaid who assured her that the room was untenanted; and, as the daughter did not believe this obtained a key and showed her the bed which apparently had not been slept in. The story can be lengthened to any degree by giving an account of the daughter's interviews with various people; the maitre d'hotel; the waiters; the cabman who drove her from the station; etc., all of whom gave the same reply, namely that she arrived alone at the hotel without her mother. The story has been used to test the ingenuity of many legal brains. It is thought that. only one of these provided the rational and supposedly true explanation, namely that the mother did arrive with the daughter, but died in the night from plague which she had contracted while abroad. A case of plague in Paris at this time would have wrecked the prospects of the exhibition, so the body was removed secretly at night, and all who had seen the deceased lady during life were bribed not to admit it.

Though not requiring the same degree of ingenuity, the following three instances, related by Thomas Hall Shastid in the American Journal of Ophthalmology may prove interesting. The first concerns a presbyope who was seen by Shastid every 6 months for a " check up " of his refraction. He suffered from headaches after reading which completely disappeared for a short period after his check up, only to appear again later. A full general examination failed to disclose any cause for this anomalous state of affairs, which remained unexplained until the patient's wife was seen. Her words were "Well, you see, hubby at night is always very tired, or else lazy. So, after dinner he used to sit in the living room and go to reading with his distance glasses, his near glasses being upstairs, therefore too far away for him to get them. He always expected to read ' just for two or three minutes.' But always, of course, he would stick to the job for two or three hours. Next day he would have a frightful headache." After each check up, however, the man would be sufficiently interested in his eyes to get and use the near glasses for night reading, though after a few days he would fall into the old habit of using his distance glasses for this purpose. Needless to say a pair of bifocals cured him of headaches.

A second case was a man who already had bifocals but from time to time would suffer from severe headaches. He was a small man and his occupation necessitated frequent conversations with other men on the public streets. Being short he had to look through the upper, distance, portion of his glasses, and the strain of trying to see the facial expressions of his interlocutors at perhaps two feet, through distance glasses brought on headaches. In this case they were completely cured by provision of a pair of $+1 \cdot 25 \mathrm{D}$. spheres 
in a grab front to be worn whenever he was talking to men he could not look down on.

The third case was again a patient with bifocals who found her glasses excellent for distance but productive of much blurry vision when she looked through the lower segments for reading. Examination of her glasses showed that the temples were just a trifle loose so that she was frequently putting her fingers against the lower part of her lenses so as to push the glasses higher up her nose, thus fogging them. Tightening the temples effected an immediate cure. The patient, though a highly educated woman, had been unable to make this simple observation herself.

\section{COUNCIL OF BRITISH OPHTHALMOLOGISTS}

\section{Annual Report}

THE Council presents its report for the year 1929-30. At the first meeting the following were elected as officers :-President, $\mathrm{Mr}$. J. Herbert Fisher; Vice-Presidents, Sir W. Tindall Lister, Sir J. Herbert Parsons; Hon. Treasurer, Mr. M. S. Mayou ; Hon. Secretary, Mr. Frank Juler. The following were appointed to serve on the Executive Committee :- The President and Secretary (ex officiis) with Mr. Treacher Collins, Sir W. Lister, Sir J. H. Parsons, Messrs. Mayou, Goulden and Williamson-Noble.

Report on admissions to Ophthalmia Schools at White Oak, Swanley.-A deputation from the Council attended at the Ministry of Health with proposals to facilitate the admission of children from the extra-metropolitan areas into the schools. The obstacle to extending the use of the schools is financial, and little hope was held out by the representatives of the Minister that any assistance could be afforded by the Ministry. It was pointed out that the cost of maintenance per child would diminish if the number of children were increased. The Board of Education has been approached in regard to the advantages of specialist examination of children in extra-metropolitan schools, since the Council has reason to believe that a certain amount of ocular disease, which would benefit by residential treatment at Swanley, escapes detection.

Ophthalmic Benefit.-Since the last report, certain developments have taken place in the possible methods of administration of ophthalmic benefit, and at a joint meeting of the Executive Committees of the Council and the British Medical Association a prolonged discussion on policy took place. As a result the Association invited the Council to nominate three representatives to 